\title{
Investigating socio-cultural factors affecting college students' attitudes towards opposite sex relation: a case of Shiraz University
}

\author{
Dr.YaserRastegar ${ }^{1}$, SedigheAlborzi ${ }^{2}$, EbrahimJafari $^{3}$
}

\begin{abstract}
One new emerging social phenomenon in the current Iranian society is the opposite sex relations have caused some concerns on a social scale, since it has faced family, religion and marriage with challenges. Accordingly, the present paper, the factors affecting college students' attitudes towards opposite sex relation was examined. To this end, a survey was used and 375 college students were selected through multistage stratified sampling method participated in the study, Fishbein and Ajzen theories, Inglehard and Sap social changes theories were adopted. A questionnaire was applied to collect the require data.

The results indicate that the hypotheses of gender, living place, religious beliefs, using the communicative instrument, family's attitudes, parents' attitudes and extent of opposite relation are confirmed and the hypothesis related to family intimacy was rejected. Moreover, 31.4\% of students ha positive attitudes, $43.1 \%$ was moderate in their attitudes and $25.5 \%$ had negative attitudes toward the opposite sex relation. Also, the participants' families' attitudes was more negative and comparing boys and girls, female subjects showed more disagreement versus male subjects. In conclusion, the culture-dependent variables of socialization more considerably affected the participants' attitudes towards opposite sex relations.
\end{abstract}

Keywords: attitude, opposite sex relation, religious beliefs

\section{INTRODUCTION}

What confuses our current generation is the conflict between living in an Islamic society with Iranian culture and the interaction with other civilizations through satellite channels and the Internet that tend to connect different nations in an unprecedented manner. Our current generation should be able to coordinate social customs and traditional attitudes, religious values and family conditions with the new ideas and attitudes peculiar to the modern world. Every society, group or tribe adopts certain values and attitudes that even include table manners, clothing style, behavior and other daily and social issues.

One of the social-cultural issues in our society is the boy-girl friendship. The issue is not fully recognized and solved in our society. Although the tendency to develop such relationship arises from physiological-psychological and social needs, it has been treated in different ways by different religions, schools and cultures. That what pattern the youth follow depends on various factors (Yusefi et al., 2007:153). The emergence of the issue and changes in private boy-girl relationship has caused concerns in families, religious leaders and community, cultural authorities and youth organization policy makers. Therefore, type of boy-girl $(\text { non-mahram })^{4}$ relationship is a social issue in terms of cultural and religious norms and values in Iran. Charles Wright Mills contends that a general social issue is a public issue that emerges when people notice their social values are overlooked or threatened globally (Mills, 2002:23). DanielineLuzic considers that a social issue is a wrong, problematic, common and changeable situation that should be changed (Luzic, 2004:25).

One of the issues creating tension and conflict in young people is boy-girl relationship consistent with cultural, religious, social and family norms. While boys and girls have free relationships in many countries, Iranian

1. Assistant Professor, Department of Social Sciences, University of Hormozgan. Email: Rastegar@hormozgan.ac.ir

2. Ph.D Student in Sociology, Department of Sociology, Shiraz University. Email: Alborzi254@gmail.com

3.M.A ofSociology, Department of Sociology, Shiraz University. Email: Ebrahimi_f @ gmail.com

${ }^{4} \mathrm{~A}$ woman who is not considered as a close relative and member of the immediate family

DOI: 10.9790/0837-2109015866 $\quad$ www.iosrjournals.org $\quad 58 \mid$ Page


youths do not know how to deal with this issue. There are different views as to how the relationship should be with the opposite sex, ranging from the most liberal to the strictest views (Mirzaie\&Barghmadi, 2010). One of our educational principles is to determine the limits, characteristics and quality of male-female relationship based on Islamic values.One of the distinguishing differences of Islamic value system is the criteria for boy-girl relationship, particularly after puberty, which is an important religious consideration. This has been solved in the West based on consensus, or in better words, personal desire.

Nowadays, some families are deviated and confused in teaching their children due to the prevalence of anti-religion tendencies in society. On the other hand, some parents exert too strict rules for relationship on their children, which may even hamper them from playing the roles pertaining to their gender identity in future. A third group tend to be passive and believe that free and even libertine boy-girl relationship, as is common in the West, contributes to social development of children (Ahmadi, 2006:3). Psychologists have enumerated the disadvantages of such relationship such as emotional disorders, negative attitude toward one's appearance, distortion of identity, jealousy, alcohol and drug abuse, poor academic performance, unwanted pregnancy, increased violence in dates, sexually transmitted diseases such as AIDS, premature marriage, suspicion against spouse, delinquency and family conflicts (Etaugh\& Bridges, 2004:36).

The emergence of this phenomenon in our society may exert structural effects on social institutions and gradually pose challenges to family and marriage institutions. Increased number of singles, increased marriage age, increased divorce rate, decreased marriage rate, increased number of illegitimate children, marital and family conflicts are examples of such challenges (Movahed et al., 2006:146). Still, relationship with the opposite sex and thinking of this issue is part and parcel of real adolescence life. Thus, adolescents need to gain knowledge and appropriate information in order to establish a healthy relationship with the opposite sex. Gaining knowledge helps adolescents change their attitudes. Adolescents' behavior changes over time with the accumulation of modified attitude (Shams, 2006).

Since human behavior is fueled with some subjective factors, accurate understanding of human behaviors requires understanding their attitude toward a given issue. People may not act without a background and certain mindset so that behaviors are influenced by what people understand and think about them. Attitude is the tendency toward a certain type of behaviorso that behavior depends on attitude. Since young people experience a new and different atmosphere as they enter the university, they adopt certain attitudes during their studies that may have a key role in their future. Thus, the present study investigates the factors contributing to the Shiraz University students' attitude toward boy-girl relationship.

\section{Literature review \\ Research in Iran}

DehghanTanha et al. (2013) studied family function and religious orientation, attitude toward premarital relationship and its outcomes in the students with and without relationship with the opposite sex. They studied a number of 500 students. The results of path analysis to predict the attitude toward premarital relationship showed that solidarity among family members could predict a negative attitude toward premarital relationship indirectly through reducing external religious orientation and directly through increasing internal religious orientation. Moreover, solidarity among family members could predict a positive attitude toward premarital relationship indirectly only through increasing internal religious orientation. The results of path analysis to predict the outcomes of premarital relationship in the students having relationship with the opposite sex revealed that solidarity among family members could indirectly predict a high score in anxious relationship and a low score in relationship with God through decreasing external religious orientation. Furthermore, solidarity among family members could predict the anxiety associated with premarital relationship only indirectly through increasing external religious orientation. The results suggested that internal and external religious orientations increased the anxiety associated with relationship with the opposite sex.

Seyedan and NajafiNezhad (2012) investigated the factors contributing to women's attitude toward the opposite sex. They conducted a survey on female students aged 16-18 years. The research sample consisted of 381 students selected using quota sampling method. The results showed that $45.7 \%$ of female students had a positive attitude toward relationship with the opposite sex while $32.3 \%$ and $22 \%$ had mediocre and negative attitudes, respectively. Results of testing the research hypotheses revealed a significant relationship of the girls' attitude toward opposite-sex relationship with family and friends' attitudes, beliefs, values and religiosity, lifestyle and socio-economic status. Results of multiple regression analysis indicated that family attitude, values and religiously, and friends' attitudes accounted for $45 \%$ of the variance in the dependent variable.

Farahani et al. (2012) examined the impact of premarital relationship with the opposite sex on marriage age and desire to marry. In the first phase of their survey, they studied 2031 students aged 18-40 years from seven state and Azad universities in Tehran. The sample was selected using a two-stage cluster sampling method. They collected the data using a standardized questionnaire. While controlling for sex, the results showed that socio-economic status and advanced premarital relationship were the key determiners of increased 
marriage age among students. Accordingly, the experience of advanced premarital relationship could increase the marriage age by two years. Besides, the findings showed a clear gender difference of premarital friendship and relationship with desire to marry. Premarital friendship and advanced relationship had a significant correlation with stronger desire to marry in girls. However, advanced premarital relationship had a significant correlation with weaker desire to marry in boys. Finally, social friendship with the opposite sex had no significant relationship with desire to marry in boys.

\section{RESEARCH IN FOREIGN COUNTRIES}

Patrick and Beckenbach (2009) studied male perception of intimacy in a qualitative study. They conducted semi-structured interviews with five men aged 21-50 years two of whom were married, two single and one engaged. They categorized the result of interviews into three themes: a global definition of intimacy, the role of masculinity and intimacy risks. Then they investigated the effect of these categories on men's perception of intimacy. The definitions of intimacy highlighted two aspects: definitions based on a sense of intimacy and definitions based on the action/behavior that displays intimacy. With regard to the actions denoting intimacy, sharing was one of the key components. Rather than focusing on sharing a single aspect, men emphasized various levels of sharing with their partner. This suggested that it was important for men to express their emotions in a relationship. That is, men are interested in talking with their partners about their emotions and should be cared for emotionally. Considering sharing, the respondents asserted that a man could be himself in intimate relations; that is, he could express his worst mental states without any fear of recrimination. Intimacy with the opposite sex allows men to be themselves, and this is totally different from what they feel when with men. Trust also constitutes an important part of intimacy. Interpersonal trust between intimate partners is different from that between friends. Sexual relationship is further associated with intimacy. Most of the men observed that sexual relationship signaled an intimate relationship though they differed as to the importance they attached to it. Some of the respondents believed that the importance of sex was exaggerated because of the stereotypes about men. Another respondent, however, believed that sexual relationship could help continue or stop a relationship. It seems that men had different ideas about the experience of intimacy in sexual relationship. With regard to the impact of gender on intimacy, the participants contended that masculinity involves supporting, saving and anchoring roles. They believed that masculinity dominated femininity, and dominance was associated with the retention of power in a relationship. Besides, their gender, masculinity, did not allow them to become vulnerable at the presence of other males. Therefore, relationship with women was the only place where men could express their fears or emotions without losing their sense of convenience andauthority. With regard to intimacy, most of the men were concerned with experiencing a relationship with a partner who could maintain their trust. On the other hand, intimacy is a potential threat to men as it requires vulnerability and sharing. Still, experienced intimacy may not be separated from sociability processes and masculine sociability teachings.This indicates that social structures should also be addressed while we study intimate relationships. All men in the study had the need and desire for intimacy and knew that the expectations associated with masculinity role affected their intimacy process. Men consider intimacy as an essential space where they can meet themselves and be relived of masculinity restrictions. However, they had no intention whatsoever to give up 'their being a man'. The findings of this study revealed the impact ofpatriarchal structure on the intimacy process. It is highly suitable to study this issue in Iran where a patriarchal structure is at work that is supported by both genders.

Johnson (2004) studied gender, ranking and relationship differences in terms of emotional closeness among teenage friends. Johnson addressed the relationship among gender, type of friendship and emotional closeness in teenagers. In this regard, a number of 270 adolescents were surveyed from different schools and colleges. The results showed that female adolescents felt more emotional closeness than male adolescents. However, male adolescents knew their friends longer than female adolescents did. Female adolescents were found to spend more time with their friends and feel more closeness and commitment to their friends. In addition to gender differences in emotional closeness, the difference was also significant in type of relationship (i.e. same-sex or opposite-sex relationship). Adolescents knew their same-sex friends longer than they did their opposite-sex friends, spent more time with them and showed greater commitment to them. Younger adolescentshad greater closeness and coherence with their same-sex friends while older ones felt the same toward their opposite-sex friends.

\section{THEORETICAL FRAMEWORK}

Fishbein and Ajzen's theory

Fishbein and Ajzen's theory is derived from expectation-value model in which a behavior is subject to the benefit expected of it and the value it has for the actor. An actor's attitude is formed based on the relationship between expectation and value. There is a complex relationship between attitudes and behavior, which is not always a direct relation. Still, an individual's attitude toward an issue affects the way he behaves to deal with it. 
Expectation-value model is subsumed under the theory of reasoned action whereby the immediate reason for behavior, i.e. intention, is a conscious decision to engage in an action. Two determiners of intention are attitude toward behavior and subjective norm. Attitude toward behavior is the outcome of expectation in the value outcomes (Bohner\&Wänke, 2003: 208-209). The second determiner of behavioral intention is the subjective norm that originates from the outcomes each of which emanating from the idea that they are the reference (person or group). Thus, the individual thinks he should behave in a certain way, and motivation should follow this reference point (ibid: 209). While directly affecting behavioral intention, subjective norm also affects behavior indirectly by influencing attitudes. As discussed, inFishbein and Ajzen's theory, subjective norm represents the social influence and pressure on an individual to exhibit a particular behavior. That is, the individual is concerned with how much his behavior is approved of or reproached by other people or groups that function as a frame of reference. They may include parents, peers, teachers and others. This variable is further divided into two subsets:

A) Others' expectation: is the expectation that how others would judge a behavior from the individual.

B) The individual's motivation to follow others' expectations: is concernedwith if it is important for the individual what others say about him (Rafipur, 1993: 11).

Sapp and Harrod's theory

While studying eating beef, Sapp and Harrod addressed social acceptability in addition to Fishbein and Ajzen's variables. They believe that social expectations contribute to the emergence of intention. They referred to reference group theory in general and drew upon Shibutani's definition of reference group in particular. Shibutani used the term 'general reference group' that functions as a frame of reference and reflects the beliefs of a wider social system. Thus, people understand the world around them through the eyes of the reference (Sapp \&Harrod, as cited in Rafipur, 1993: 12,). The reference group may consist of any set of people (e.g. family, friends, etc.). The reference group provides a frame of evaluation based on which the members of the social system or group tend to control and evaluate themselves and others. In this regard, whatever is established as a group values scale would affect the judgment and evaluation of each group member (ibid). Sociologists contend that the reference group has the following characteristics: a source of inspiration for developing attitudes, evaluations and behaviors; a source ofgoal reception; a model of identification; a source of providing the norms making meaning in life; a personal guideline; and a source of determining evaluation criteria. Besides, it realizes the generalized others to whom the individual relates, and the individual aspires to establish relationship with them and seek their approval. It also serves as a source of providing evaluation tools.

According to Singer, the reference group is one that the individual tries to follow as a model whether being a member or not. In sum, a reference group can be considered as a group or individual serving as a model when the individual is making evaluations and behaving based on his expectations of them. What seems to be a common element in most of the above characteristics is the potential of the individual's behavior being evaluated based on the reference group. That is, the individual evaluates himself in an issue based on the reference group criteria to decide if he should adopt a positive or negative attitude toward it. According to Rafipur (1993), Sapp and Harrod did not come up with a novel idea when they addressed the reference group and its impact on personal attitudes as Fishbein and Ajzen addressed the same idea earlier by referring to the subjective norm so that the term 'important others' is introduced here. Like Fishbein and Ajzen, Sapp and Harrod considered the two indicators of parents' attitude and peers' attitude to represent the subjective norm (Rafipur, 1993:13).

\section{Inglehart's theory of culture shift}

Inglehart believes that what distinguishes different societies is their attitudes, values and basic skills. In other words, different societies have different cultures. Cultural shiftis gradual and is the reflection of the changes in constructive experiences that shape different generations. Thus, traditional values and norms are ingrained in past generations while new values are widely prevalent in younger generations. As younger generations replace older ones, the dominant worldview changes in the society (Inglehart, 2003:1). There are two approaches as to the value system of different social classes. One is the needs theory.Inglehart's theory of materialism and post-materialism is a subset of needs theory. In his works like 'The Silent Revolution' and 'Culture Shift in Advanced Industrial Society', he addresses the mechanism of cultural change in the West over the past decades. His theory may be summarized as follows:

Some changes in the social system (e.g. economic changes) lead to changes in the micro-levels (e.g. skills and values). In turn, these changes at the individual level produce outcomes in the system. Inglehart's classification of values is in terms of materialism and post-materialism values defined based on Maslow's hierarchy of needs. He contends that culture and values are subject to socio-economic conditions in the society (ibid:13). This culture distinguishes people in different societies. Based on the results of European Social Survey, worldwide values survey and panel studies around 1981, he concluded that culture has significantly changed in the developed industrial societies over the last decades due to economic, technological, social and 
political changes. Cultural change is gradual and reflects the changes in constructive experiences that shape different generations. Thus, traditional values and norms are ingrained in past generations. As younger generations replaced older ones, the dominant worldview changed in these societies. In sum, Inglehart's theoretical framework of values shift is based on two important hypotheses.

1. Scarcity hypothesis: posits that an individual's values reflect his socio-economic environment where the individual attaches the highest subjective value to the things that are scarcely supplied.

2. Socialization hypothesis: proposes that the relationship between socio-economic environment and adaptationinduced value priorities is not immediate, but there is a considerable time lag because key human values denote conditions persisting before the individual's puberty. The socialization hypothesis complements the scarcity hypothesis. Based on this hypothesis, social values do not change immediately but gradually. The change at a larger scale occurs when a younger generation replaces the adult generation in a society. After a period of rapid improvement in physical and economic security, one may expect to witness a considerable difference in value priorities between the younger and older age groups (Inglehart, 1980:198). These two hypotheses determine the process of value change together. Besides, value change is subject to differences in the environment where different generations are raised. Inglehart does not talk about a generation. Still, he seems to agree withMannheim about generation changes positing that a generation is the congregation of people who experience the same common environment that highly affects them. Under such circumstances, value change is a social process, influenced by generations, in which social development affects people's attitudes.

A synthesis of theories is used in the present study. The main theoretical framework of the study hinges on Fishbein and Ajzen's theory of attitude and Sapp and Harrod's theory of the effect of reference groups on the individual. Inglehart's culture shift was also drawn upon to account for the concept of attitude. Fishbein and Ajzen believe that people's intention is subject to two factors: tendency toward a behavior and subjective norm. Tendency is subject to the expected outcome and outcome evaluation. Subjective norm is subject to others' expectation and motivation to comply with others. According to Sapp and Harrod, a reference group provides an evaluation framework based on which the members of the social system or group tend to control and evaluate themselves. In this regard, whatever is ingrained as a group values scale would affect the judgment and evaluation of all group members. As discussed, based on Inglehart's socialization hypothesis, the relationship between socio-economic environment and adaptation-induced value priorities is not immediate, but there is a considerable time lag because key human values denote conditions persisting before the individual's puberty. Friends' relationship with the opposite sex, family's attitude toward relationship with the opposite sex, experience of relationship with the opposite sex and parental supervision were the variables extracted from Fishbein and Ajzen's theory and Sapp and Harrod's ideas. The socio-economic variables were extracted from Inglehart's theory of the relationship of socio-economic status with values. Some variables such as gender, marital status and age were addressed consistent with previous studies.

\section{RESEARCH HYPOTHESES}

- There is a relationship between gender and attitude toward boy-girl relationship.

- There is a relationship between place of residence and attitude toward boy-girl relationship.

- There is a relationship between religious beliefs and attitude toward boy-girl relationship.

- There is a relationship between using means of communication and attitude toward boy-girl relationship.

- There is a relationship between family's attitude toward relationship with the opposite sex and attitude toward boy-girl relationship.

- There is a relationship between parental supervision and attitude toward boy-girl relationship.

- There is a relationship between closeness of family members and attitude toward boy-girl relationship.

- There is a relationship between peers' relationship with the opposite sex and attitude toward boy-girl relationship.

\section{METHODOLOGY}

This study is a quantitative research adopting a survey design. The population of the study consisted of all students at Shiraz University ( $\mathrm{N}=16000)$. The research sample was computed using Cochran's formula to be 350 students. The sample size was increased to 375 subjects in order to assure greater accuracy. The participants were selected using multistage stratified random sampling. The researcher administered a number of 375 questionnaires to the respondents to collect the data. SPSS 16 was used to analyze the data. 
VI.

RESULTS

Table 1. Results of testing the differences in the attitude toward boy-girl relationship based on the respondents' gender

\begin{tabular}{|c|c|c|c|c|c|}
\hline Variable & $\begin{array}{c}\text { Frequen } \\
\text { cy }\end{array}$ & Mean & SD & T & Sig \\
\hline Female & 208 & 38.4 & 13.04 & \multirow{2}{*}{-3.09} & \multirow{2}{*}{0.002} \\
\hline Male & 145 & 42.7 & 12.26 & \\
\hline
\end{tabular}

As shown in Table 1, the mean score of the attitude toward boy-girl relationship is larger in male respondents. Thus, men had a more positive attitude toward boy-girl relationship. The difference in the attitude toward boygirl relationship was significant between male and female respondents. Therefore, the above hypothesis is supported.

Table 2.Results of testing the differences in the attitude toward boy-girl relationship based on the respondents' place of residence

\begin{tabular}{|c|c|c|c|c|c|}
\hline Variable & $\begin{array}{c}\text { Frequen } \\
\text { cy }\end{array}$ & Mean & SD & T & Sig \\
\hline Dormitory & 239 & 37.9 & 12.7 & \multirow{2}{*}{-5.01} & \multirow{2}{*}{0.000} \\
\hline Other & 113 & 45.0 & 11.7 & & \\
\hline
\end{tabular}

As shown in Table 2, the mean score of the attitude toward boy-girl relationship is larger in the students not living in the dormitory so that the students who lived off-campus had a more positive attitude toward such relationship. Based on the observed difference in the mean scores, there is a significant difference in the attitude toward boy-girl relationship between on-campus and off-campus students with $99 \%$ certainty. Thus, the above hypothesis is supported.

Table 3.Results of correlation test and regression analysis of the relationship between religiosity and attitude toward boy-girl relationship

\begin{tabular}{|c|c|c|c|c|c|c|c|c|c|}
\hline Variable & $\mathrm{R}$ & $\mathrm{R}^{2}$ & $\mathrm{R}^{2} \mathrm{Ad}$ & $\mathrm{SD}$ & $\begin{array}{c}\mathrm{B} \\
\text { coefficient }\end{array}$ & Beta & $\mathrm{T}$ & $\mathrm{F}$ & $\mathrm{Sig}$ \\
\hline Religious beliefs & 0.619 & 0.383 & 0.382 & 10.1 & -0.775 & -0.619 & -14.7 & 218.2 & 0.000 \\
\hline
\end{tabular}

As shown in Table 3, there is a strong correlation between religious beliefs and attitude toward boy-girl relationship $(\mathrm{R}=0.619)$. The value of $\mathrm{R}^{2}(0.383)$ indicates that religious beliefs can account for 0.383 of the variance in the dependent variable. Beta coefficient (-0.775) indicates that an increase as much as one unit in the independent variable (religious beliefs) will decrease 0.775 units in the dependent variable (attitude toward boygirl relationship). Considering the values of $\mathrm{T}=-14.7, \mathrm{~F}=218.2$ and $\mathrm{Sig}=0.000$, the correlation observed between the two variables is significant with $99 \%$ certainty. Thus, the above hypothesis is supported.

Table 4.Results of correlation test and regression analysis of the relationship between using means of communication and attitude toward boy-girl relationship

\begin{tabular}{|c|c|c|c|c|c|c|c|c|c|}
\hline Variable & $\mathrm{R}$ & $\mathrm{R}^{2}$ & $\mathrm{R}^{2} \mathrm{Ad}$ & $\mathrm{SD}$ & $\begin{array}{c}\mathrm{B} \\
\text { coefficient }\end{array}$ & Beta & $\mathrm{T}$ & $\mathrm{F}$ & $\mathrm{Sig}$ \\
\hline $\begin{array}{c}\text { Using means of } \\
\text { communication }\end{array}$ & 0.224 & 0.050 & 0.047 & 12.5 & 0.671 & 0.224 & 4.3 & 18.5 & 0.000 \\
\hline
\end{tabular}

Based on Table 4, there is a weak correlation between using means of communication and attitude toward boygirl relationship $(\mathrm{R}=0.224)$. The value of $\mathrm{R}^{2}(0.050)$ shows that using means of communication could account for 0.050 of variance in the dependent variable. Beta coefficient $(0.671)$ indicates that an increase as much as one unit in the independent variable (using means of communication) will increase 0.671 units in the dependent variable (attitude toward boy-girl relationship). Considering the values of $\mathrm{T}=4.3, \mathrm{~F}=18.5$ and Sig=0.000,the correlation observed between the two variables is significant with $99 \%$ certainty. Thus, the above hypothesis is supported.

Table 5.Results of correlation test and regression analysis of the relationship between family's attitude toward relationship with the opposite sex and attitude toward boy-girl relationship 


\begin{tabular}{|c|c|c|c|c|c|c|c|c|c|}
\hline Variable & $\mathrm{R}$ & $\mathrm{R}^{2}$ & $\mathrm{R}^{2} \mathrm{Ad}$ & $\mathrm{SD}$ & $\begin{array}{c}\mathrm{B} \\
\text { coefficient }\end{array}$ & Beta & $\mathrm{T}$ & $\mathrm{F}$ & $\mathrm{Sig}$ \\
\hline $\begin{array}{c}\text { Family's } \\
\text { attitude } \\
\text { toward } \\
\text { relationship } \\
\text { with the } \\
\text { opposite } \\
\text { sex }\end{array}$ & 0.606 & 0.368 & 0.366 & 10.1 & 1.103 & 0.606 & 13.8 & 192.4 & 0.000 \\
\hline
\end{tabular}

As illustrated in Table 5, there is a strong correlation between family's attitude toward relationship with the opposite sex and attitude toward boy-girl relationship $(R=0.606)$. The value of $R^{2}(0.368)$ indicates that family's attitude toward relationship with the opposite sex could account for 0.368 of the variance in the dependent variable. Beta coefficient (1.103) indicates that an increase as much as one unit in the independent variable (family's attitude toward relationship with the opposite sex) will increase 1.103 units in the dependent variable (attitude toward boy-girl relationship). Considering the values of $\mathrm{T}=13.8, \mathrm{~F}=192.4$ and $\mathrm{Sig}=0.000$, the correlation observed between the two variables is significant with $99 \%$ certainty. Thus, the above hypothesis is supported.

Table 6.Results of correlation test and regression analysis of the relationship between parental supervision and attitude toward boy-girl relationship

\begin{tabular}{|c|c|c|c|c|c|c|c|c|c|}
\hline Variable & $\mathrm{R}$ & $\mathrm{R}^{2}$ & $\mathrm{R}^{2} \mathrm{Ad}$ & $\mathrm{SD}$ & $\begin{array}{c}\mathrm{B} \\
\text { coefficient }\end{array}$ & Beta & $\mathrm{T}$ & $\mathrm{F}$ & $\mathrm{Sig}$ \\
\hline Parental supervision & 0.295 & 0.087 & 0.085 & 12. & -1.517 & -0.295 & -5.7 & 33.5 & 0.000 \\
\hline
\end{tabular}

As shown in Table 6, there is a weak correlation between parental supervision and attitude toward boy-girl relationship $(\mathrm{R}=0.295)$. The value of $\mathrm{R}^{2}(0.087)$ indicates that parental supervision could account for 0.087 of the variance in the dependent variable. Beta coefficient (-1.517) reveals that an increase as much as one unit in the independent variable (parental supervision) will decrease 1.517 units in the dependent variable (attitude toward boy-girl relationship). Considering the values of $\mathrm{T}=-5.7, \mathrm{~F}=33.5$ and $\mathrm{Sig}=0.000$, the correlation observed between the two variables is significant with $99 \%$ certainty. Thus, the above hypothesis is supported.

Table 7.Results of correlation test and regression analysis of the relationship between closeness of family members and attitude toward boy-girl relationship

\begin{tabular}{|c|c|c|c|c|c|c|c|c|c|}
\hline Variable & $\mathrm{R}$ & $\mathrm{R}^{2}$ & $\mathrm{R}^{2} \mathrm{Ad}$ & $\mathrm{SD}$ & $\begin{array}{c}\mathrm{B} \\
\text { coefficient }\end{array}$ & Beta & $\mathrm{T}$ & $\mathrm{F}$ & Sig \\
\hline $\begin{array}{c}\text { Closeness of } \\
\text { family members }\end{array}$ & 0.084 & 0.007 & 0.004 & 12.8 & -0.280 & -0.084 & -1.5 & 2.4 & 0.116 \\
\hline
\end{tabular}

As shown in Table 7, there is a weak correlation between closeness of family members and attitude toward boygirl relationship $(\mathrm{R}=0.084)$. The value of $\mathrm{R}^{2}(0.087)$ specifies that closeness of family members could account for only 0.007 of the variance in the dependent variable. Considering the values of $\mathrm{T}=-1.5, \mathrm{~F}=2.4$ and $\mathrm{Sig}=0.116$, the correlation observed between the two variables is not significant. Thus, the above hypothesis is rejected.

Table 8.Results of correlation test and regression analysis of the relationship between peers' relationship with the opposite sex and attitude toward boy-girl relationship

\begin{tabular}{|c|c|c|c|c|c|c|c|c|c|}
\hline Variable & $\mathrm{R}$ & $\mathrm{R}^{2}$ & $\mathrm{R}^{2} \mathrm{Ad}$ & $\mathrm{SD}$ & $\begin{array}{c}\mathrm{B} \\
\text { coefficient }\end{array}$ & Beta & $\mathrm{T}$ & $\mathrm{F}$ & Sig \\
\hline $\begin{array}{c}\text { Peers' relationship } \\
\text { with the opposite sex }\end{array}$ & 0.702 & 0.494 & 0.492 & 9.1 & 1.578 & 0.702 & 18.2 & 332.2 & 0.000 \\
\hline
\end{tabular}

As illustrated in Table 8, there is a strong correlation between peers' relationship with the opposite sex and attitude toward boy-girl relationship $(R=0.702)$. The value of $R^{2}(0.494)$ shows that peers' relationship with the opposite sex could account for 0.494 of the variance in the dependent variable.Beta coefficient (1.578) reveals that an increase as much as one unit in the independent variable (peers' relationship with the opposite sex) will increase 1.578 units in the dependent variable (attitude toward boy-girl relationship). Considering the values of $\mathrm{T}=18.2, \mathrm{~F}=332.2$ and $\mathrm{Sig}=0.000$, the correlation observed between the two variables is significant with $99 \%$ certainty. Thus, the above hypothesis is supported. 


\section{DISCUSSION AND CONCLUSION}

Nowadays, premarital boy-girl relationship has sparked off heated debates in Iran. Interactions between the two sexes have undergone drastic changes. Sociology aims to describe, explain and interpret human interactions and to address the role of causation in structural changes. It also studies the impact of structural factors on personal actions in order to imbue the society with knowledge and understanding.Considering the importance of the relationship between the two sexes and the changes occurring in such relationship, we addressed the factors contributing to the students' attitude toward boy-girl relationship in the present study. The results of descriptive statistics showed that only did $25.5 \%$ of the students have a negative attitude toward premarital boy-girl relationship while about half of the respondents $(43.1 \%$ ) had a moderate and $31.4 \%$ had a positive attitude toward such relationship. The results by gender showed that girls had a much more negative attitude than boys toward such relationship. Previous studies have also reported a more negative attitude toward boy-girl relationship in women (Jokar, 2004). Overall, the results suggested that the students had a positive attitude toward premarital boy-girl relationship. However, students' families tend to adopt a more conservative attitude toward the issue. This indicates generational differences in families about thevalues around boy-girl relationship. Bivariate analysis showed that gender, place of residence, religious beliefs, family's attitude, parental supervision, experienced friendship with the opposite sex, using means of communication and peers' relationship with the opposite sex had a significant correlation with the dependent variable. Nevertheless, closeness of family members did not show a significant correlation with the dependent variable.

Premarital relationship between the two sexes denotes dramatic social changes in the public domain. As Giddens suggests, changes in the private sphere affects the changes in the public sphere and vice versa. Based on the present findings, one may conclude that students are interested in establishing relationship with the opposite sex. Although this phenomenon has emerged as widely as this over the last few years, it is expected to increase rapidly in the next years. Consistent with the findings of Azad et al. (2000) and Ministry of Culture and Islamic Guidance (2003), our results suggested the development and reproduction of new values in boy-girl relationship. Our claim is supported by the results obtained in this study. We claim that attitudinal and value changes have occurred/are occurring among young people about boy-girl relationship. Young people have attitudinal and value orientations considerably different from that of their families. This is concluded based on the present findings. The results showed that students adopt a more positive attitude toward boy-girl relationship than their families. This is one of comparative bases for attitudinal and value changes in the society. In addition to supporting the above assertion, this finding also suggests a generation gap in families. Thus, there is a generation gap between families and children at least with regard to the values and rules of relationship with the opposite sex. Attitudinal and value changes in general and culture shift in particular do not occur overnight but slowly and gradually. In fact, it is the result of differing experiences of different generation in their socialization process. Wide-ranging changes occur when a young generation replaces an old one. Attitudinal and value changes in boy-girl relationship is a symptom of marked cultural changes occurring in our transitional society. Structural changes in the society in economic and social domains have made it difficult for young people to satisfy sexual, social and psychological needs through the traditional institution of marriage. Thus, young people may not marry early. Obviously, all actions and orientations of young people are focused on how to satisfy these legitimate but repressed needs. The society will inevitably reproduce the approaches and ways to satisfy these needs. The researcher believes that many social damages and abnormalities may be prevented in this regard by referring to the experiences of western societies. The institutions of marriage and family suffer big challenges nowadays. Thus, it is necessary for the authorities to remove the barriers to marriage and familiarize young people with the adverse effects (e.g. social, mental, physical, etc.) of friendship with the opposite sex.

\section{REFERENCES}

[1] Ahmadi, A.A. (2006). An educational analysis of boy-girl relationship in Iran. Tehran: Parents and Teachers Association Publications.

[2] Bohner, G.,\&Wänke, M. (2003). Attitudes and Attitude Change. M. SadeghiBenis (Trans.). Tehran: Savalan Publications.

[3] DehghanTanha, R., Ayati. M.,\&ShahabiZadeh, F. (2013). Family function and religious orientation: providing the models of attitude toward premarital relationship with the opposite sex and its outcomes in the students with and without relationship with the opposite sex. Psychology and Religion Quarterly, 23, 81-95.

[4] Etaugh, C., \& Bridges, A. (2004).The Psychology of Women (2nd Ed). U.S.A: Pearson.

[5] Farahani, F., Kazemipur, Sh.,\&Rahimi, A. (2012). Investigating the effect of premarital relations with the opposite sex on marriage age and desire to marry among the students at Tehran universities.Women's Strategic Studies, 15(58). 
[6] Inglehart, R. (2003). Culture Shift in Advanced Industrial Society. M. Vatr (Trans.). Tehran: Kavir Publications.

[7] Joker, B. (2004).Comparison of the attitude toward boy-girl friendship between humanities students and engineering students at Shiraz University. Proceedings of the National Conference on Students' Mental Health, TarbiatModares University, 19-29.

[8] Luzic, D. (2004).A new approach to analyzing social issues. S. Moayed Far (Trans.). Tehran: Amir Kabir Publications.

[9] Mills, C.R. (2002). The Sociological Imagination. A.M. Ansari (Trans.). Tehran: Enteshar Corporation Press.

[10] Ministry of Culture and Islamic Guidance (2003).Iranian values and attitudes: survey findings in 28 provinces. Tehran: Ministry of Culture and Islamic Guidance.

[11] Mirzaie, Kh.,\&Barghmadi, H. (2010). Relationship with the opposite sex and the factors contributing to it.Social Welfare Quarterly, 10(34).

[12] Movahed, M., et al. (2006).Investigating socio-cultural factors contributing to students' attitude toward premarital boy-girl relationship.Shiraz University Journal of Social Sciences and Humanities, 2.

[13] Rafipur, F. (1993).Investigating the villagers' attitude toward Construction Jihad. Tehran: Publications of the Center for Research and Study of Rural Issues.

[14] Shams, M. (2006).Teaching health. Available at http:// www.jeko.blogfa.com.2000

[15] Shawn, P., Beckenbach, J. (2009). Male Perceptions of Intimacy: A Qualitative study. The Journal of Men's Studies, 17 (1), 47-56.

[16] Seyedan, F.,\&NajafiNezhad, N. (2012). Factors contributing to women's attitude toward relationship with the opposite sex.Social Sciences, 9 (1).

[17] Yusefi, Z., et al. (2007). Studying the effectiveness of teaching healthy relationship by emphasizing social learning and increasing women's knowledge of harmful boy-girl relationship.Principles of Mental Health Quarterly, 35-36. 